\title{
Effect of CoCrMo Addition on Ti6Al4V/xCoCrMo Biomedical Composites Processed by Powder Metallurgy
}

\author{
Elena Mihalcea ${ }^{1} \mathbb{1}$, Luis Olmos $^{2}$, Héctor Vergara-Hernández ${ }^{1, *}$, Omar Jimenez $^{3}$, Jorge Chávez ${ }^{4}$ \\ and Dante Arteaga ${ }^{5}$
}

1 División de Estudios de Posgrado e Investigación, TecNM/Instituto Tecnológico de Morelia, Av. Tecnológico 1500, Colonia Lomas de Santiaguito, Morelia C.P. 58120, Mexico; emihalcea@itmorelia.edu.mx

2 INICIT, Universidad Michoacana de San Nicolás de Hidalgo, Fco. J. Mujica S/N, Morelia C.P. 58060, Mexico; luis.olmos@umich.mx

3 DIP, Universidad de Guadalajara, José Guadalupe Zuno 48, Los Belenes, Zapopan C.P. 45100, Mexico; omar.aleman@academicos.udg.mx

4 Departamento de Ingeniería Mecánica Eléctrica, CUCEI, Universidad de Guadalajara, Blvd. Marcelino García Barragán 1421, Olímpica, Guadalajara C.P. 44430, Mexico; jorge.chavez@academicos.udg.mx

5 Centro de Geociencias, Universidad Nacional Autónoma de México, Blvd. Juriquilla No. 3001, Querétaro C.P. 76230, Mexico; darteaga@geociencias.unam.mx

* Correspondence: hector.vh@morelia.tecnm.mx; Tel.: +52-443-335-7888

\section{check for}

updates

Citation: Mihalcea, E.; Olmos, L.; Vergara-Hernández, H.; Jimenez, O.; Chávez, J.; Arteaga, D. Effect of CoCrMo Addition on Ti6Al4V/xCoCrMo Biomedical Composites Processed by Powder Metallurgy. Metals 2021, 11, 1523. https://doi.org/10.3390/ met11101523

Academic Editor:

Andrzej Miklaszewski

Received: 22 August 2021

Accepted: 20 September 2021

Published: 26 September 2021

Publisher's Note: MDPI stays neutral with regard to jurisdictional claims in published maps and institutional affiliations.

Copyright: (c) 2021 by the authors. Licensee MDPI, Basel, Switzerland. This article is an open access article distributed under the terms and conditions of the Creative Commons Attribution (CC BY) license (https:// creativecommons.org/licenses/by/ $4.0 /)$.
Abstract: A detailed experimental and numerical investigation was performed on a Ti6Al4V/xCoCrMo biomedical composite for bone implant applications. The aim was to understand the effect generated by the addition of different volume fractions of CoCrMo particles on a Ti6Al4V matrix composite processed by powder metallurgy. Distribution of CoCrMo particles inside a matrix was observed by computed microtomography. Three-dimensional image analysis allowed for the deduction that the mechanism that permitted percolation within the powder mixture was the cluster formation at 30 vol.\% of CoCrMo and at a coordination number of Co-Co contacts of 2.8, which confirms existing models. Densification during powder compaction was driven by larger indentations at the Ti-Co contacts for lower quantities of CoCrMo than for those reaching percolation. Sintering was studied by dilatometry tests at $1130{ }^{\circ} \mathrm{C}$, and results indicated that solid-state sintering generated the formation of a rigid skeleton. This endured the stress generated by the eutectic reaction liquid, which filled the interparticle porosity, resulting in relative densities above $90 \%$. Microstructure was analyzed by SEM and X-ray diffraction, and results showed a Ti6Al4V matrix surrounded by a $\mathrm{Ti}_{2} \mathrm{Co}$ eutectic phase. In addition, the hardness of composites increased up to three times compared to the Ti6Al4V alloy. It was concluded that the best properties were obtained from 20 vol. $\%$ of CoCrMo.

Keywords: Ti6Al4V matrix composites; powder compaction; semi-solid sintering; microtomography; hardness

\section{Introduction}

$\mathrm{Ti}$ and its alloys have been widely used in the biomedical field because of their good biocompatibility, high corrosion resistance and low weight density compared to other metallic alloys also accepted, such as stainless steel and CoCrMo alloy. Although $\mathrm{Ti}$ alloys are accepted for dentistry applications because of their good combination of properties [1], they show disadvantages, such as a high melting point, lower hardness and higher oxygen affinity at high temperatures [2,3], with respect to the materials traditionally used. Reduction of the melting point can be achieved by adding some alloying elements with lower melting points and/or elements that induce eutectic reactions [4-7]. Two different processing routes, metal casting and semi-solid sintering, are available. The second one is a promising technique, as lower temperatures of processing are needed and 
the shape of compacts can be obtained with axial compaction that reduces the machinability costs, with respect to metal casting.

The sintering of liquid-phase materials has been largely used in order to obtain alloys and composites highly densified, as the liquid spreads in the porosity and fills it [8-10]. In semi-solid sintering, unlike liquid-phase sintering, the liquid is created via a eutectic reaction of two materials. Then, the liquid spreads over the surface of the solid structure, generated by the material with higher melting point, which plays a role equivalent to the matrix in composites. This process is similar to the well-known supersolidus liquid-phase sintering (SLPS), used to consolidate different metallic alloys [11-14]. The main problem that can arise during semi-solid sintering is controlling the compacts' shape, as a high quantity of liquid generates distortion of the compacts, because the liquid drops to the bottom by gravity effect, as it was reported elsewhere [15]. To minimize the distortion of compacts, there are a few key processing parameters to control, such as the quantity of liquid [16], the distribution of particles reacting to form the eutectic phase, compaction pressure [11] and sintering temperature [17].

The objective of this work was to study the effects of the addition of CoCrMo particles in a Ti6Al4V matrix to fabricate composites through semi-solid sintering that can be used in the biomedical industry, as dental and/or bone implants. To accomplish our goal, the volume fraction of CoCrMo particles was varied from 10 to $30 \%$, with a $5 \%$ increment. The distribution of such particles in the initial packing was observed by computed microtomography. Next, their effect on uniaxial compaction was studied. The sintering kinetics were evaluated by dilatometry tests and the microstructure characteristics were determined by scanning electron microscopy (SEM) and X-ray diffraction (XRD). Finally, the hardness of the composites was evaluated.

\section{Materials and Methods}

\subsection{Sample Preparation}

Atomized prealloyed Ti6Al4V and CoCrMo metal powders with spherical particles smaller than $25 \mu \mathrm{m}$ (produced by Raymor, Quebec, Canada and SANDVIK Osprey ${ }^{\mathrm{TM}}$, Sweden, respectively) were used to fabricate composites. CoCrMo particles, ranged between 10 and $30 \mathrm{vol} . \%$ with respect to the Ti6Al4V powders, were added to the matrix. The mixing process was performed in a Turbula ${ }^{\circledR}$ mixer for 30 min in dry conditions.

To determine the distribution of CoCrMo particles in the initial packing, a small quantity of each mixture was poured into a $1 \mathrm{~mm}$ diameter quartz capillary until reaching a $10 \mathrm{~mm}$ height. Then, the samples were mounted into a plastic tube, which is transparent to the X-rays, and the assembly was placed on the goniometer of a Zeiss 510 Xradia Versa computerized microtomographer to acquire 3D images of the different composites. A total of 1600 projections were taken, $360^{\circ}$ around the sample with a CCD camera of $1024 \times 1024$ pixels, with a voxel resolution of about $1 \mu \mathrm{m}$. Figure 1 a shows a $2 \mathrm{D}$ virtual slice of the mixture of powders containing $20 \mathrm{vol} \%$ of CoCrMo particles, after reconstruction of the image. Three different gray intensities are observed from Figure 1a: light gray, gray and dark gray. The gray level is determined by the attenuation of the $\mathrm{X}$-ray beam when passing through a material, which is directly related to the material density [18]. Thus, as the density of materials increases the attenuation increases. As a consequence, the denser the material, the brighter it appears in the gray level image. According to this, the light gray particles correspond to the densest material, which is the CoCrMo in our case. The gray corresponds to the Ti6Al4V particles, and the dark gray is the void space, i.e., the pores. These three phases can be easily detected in the histogram of voxel gray levels shown in Figure $1 \mathrm{~b}$. As can be observed, the three peaks are clearly separated, which makes selecting the gray level corresponding to each phase easier. By selecting the range of a peak in the histogram, it is possible to obtain a binary image with only one phase (see Ti6Al4V in Figure 1c, CoCrMo in Figure 1d and the pores in Figure 1e). A more detailed procedure has been given elsewhere [19]. This procedure was performed in 3D, but we used virtual 
2D slice views for observation. The binary images are used to determine quantitative data of each phase.

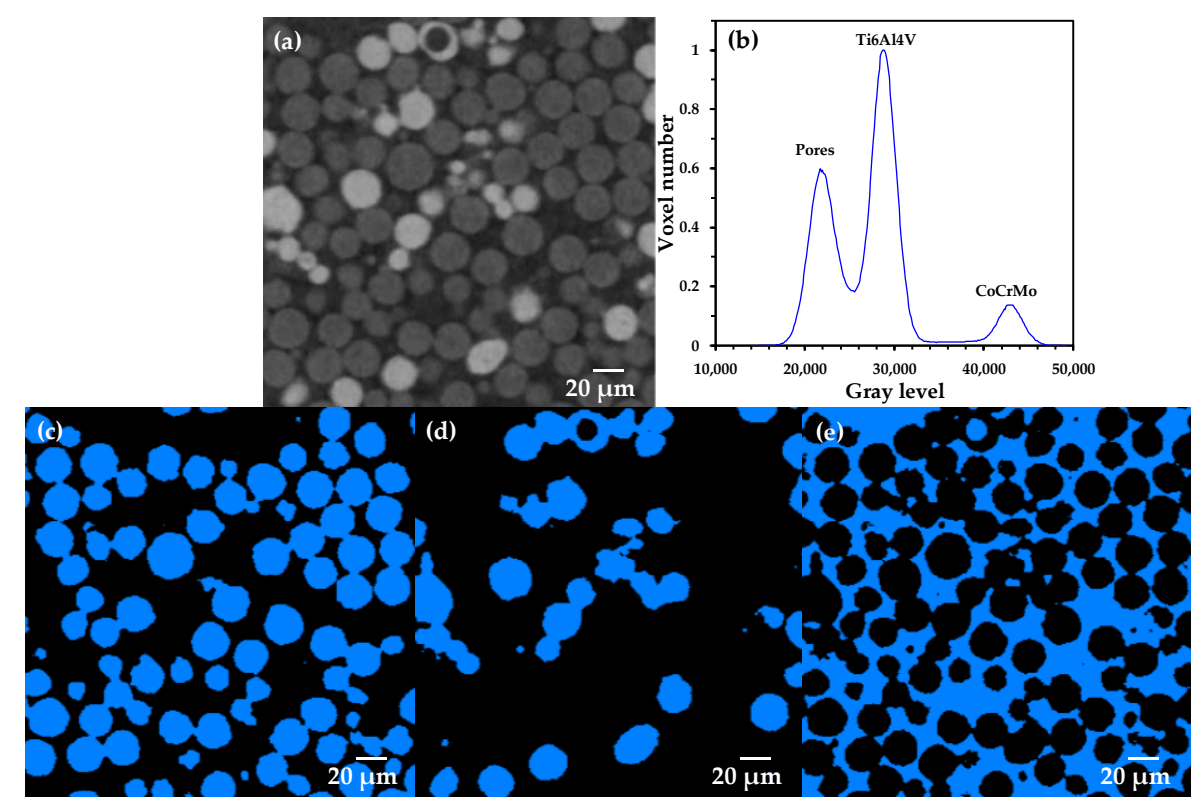

Figure 1. 2D virtual slice of Ti6Al4V/20CoCrMo composite (a,b) histogram of voxel gray levels of the complete $3 \mathrm{D}$ image. (c-e) are 2D virtual slices of the binary images of the three phases, separated by selecting the gray level in the histogram corresponding to the Ti6Al4V, CoCrMo and pores, respectively.

Green cylinders of $8 \mathrm{~mm}$ diameter and $4 \mathrm{~mm}$ height were fabricated by uniaxial compaction by pouring the mixture of powders into a stainless steel die and pressing at $450 \mathrm{MPa}$ at a strain rate of $0.5 \mathrm{~mm}-\mathrm{min}^{-1}$ using an Instron 1150 universal machine. The information of the axial displacement of the machine after correction allows for obtainment of the stress displacement curve during the compression test. Assuming that the die walls are rigid and the mass is constant, it is possible to estimate the density at any time during the tests as follows:

$$
\rho_{\mathrm{i}}=\frac{\mathrm{m}}{\mathrm{V}_{\mathrm{i}}},
$$

where $\rho_{i}$ is the instantaneous density, $m$ is the mass and $V_{i}$ is the instantaneous volume. As the diameter of the die is constant, the change in the volume is estimated from the displacement of the piston inside the die. In order to follow the densification during compression, the relative density is estimated by calculating the theoretical density for each composite with the Rule of Mixtures:

$$
\rho_{\mathrm{t}}=\rho_{\mathrm{Ti6} \mathrm{Al} 4 \mathrm{~V}} \mathrm{f}_{\mathrm{Ti} 6 \mathrm{Al} 4 \mathrm{~V}}+\rho_{\mathrm{CoCrMo}} \mathrm{f}_{\mathrm{CoCrMo}}
$$

where $\rho_{\mathrm{t}}$ is the theoretical density of the composite and $\rho_{\mathrm{Ti} 6 \mathrm{Al} 4 \mathrm{~V}}, \rho_{\mathrm{CoCrMo}}, \mathrm{f}_{\mathrm{Ti6Al4V}}$ and $\mathrm{f}_{\mathrm{CoCrMo}}$ are the theoretical density and volume fraction of Ti6Al4V and CoCrMo particles, respectively. Thus, the relative density is:

$$
\mathrm{D}_{\mathrm{i}}=\frac{\rho_{\mathrm{i}}}{\rho_{\mathrm{t}}}
$$

where $D_{i}$ is the relative density at any instant during the compression tests.

Green compacts were then sintered in a Linseis L75V vertical dilatometer at $1130{ }^{\circ} \mathrm{C}$ with a dwell time of $5 \mathrm{~min}$ under argon atmosphere. Two heating rates were used to reach the sintering temperature: $20^{\circ} \mathrm{C} / \mathrm{min}$ was used for heating from room temperature up to $1050{ }^{\circ} \mathrm{C}$. Then heating was carried out at $5^{\circ} \mathrm{C} / \mathrm{min}$ from $1050^{\circ} \mathrm{C}$ up to $1130^{\circ} \mathrm{C}$. This was a 
necessary measure to ensure that the temperature reached during the thermal cycle would stay close to the setup one, as the temperature of the furnace can increase by 10 or $20^{\circ} \mathrm{C}$ with the inertia when higher heating rates are used, as it was determined elsewhere [6].

\subsection{Sample Characterization}

The sintered composites were cut and surface-polished with SiC abrasive papers and alumina powders (until $50 \mathrm{~nm}$ particle size), successively for SEM observation. The microstructure was observed with a Tescan MIRA 3 LMU field emission scanning electron microscope (FE-SEM, TESCAN ORSAY HOLDING, a.s., Brno-Kohoutovice, Czech Republic), coupled with an energy dispersive X-ray spectrometer (Bruker, XFlash 6I30; Billerica, MA, USA) for elemental and mapping analyses. Samples were directly observed without any conductive coating and the acceleration voltage used to acquire the FE-SEM images was set at $20 \mathrm{keV}$ by using both secondary and back scattering electrons. The crystalline structure was assessed by X-ray diffraction (XRD) using a PANalytical Empyrean diffractometer. The XRD patterns were obtained by using $\mathrm{K}$ alpha copper radiation with an energy of $30 \mathrm{kV}$ and $30 \mathrm{~mA}$, with a step size of 0.2 and a time step of $1 \mathrm{~s}$ in the range of $30-80^{\circ}$. Finally, the hardness evaluation was performed on cross-sectional polished surfaces via a micro-hardness tester from Mitutoyo MVK-HVL with a load of $10 \mathrm{gf}$ and a dwell time of $15 \mathrm{~s}$.

\section{Results and Discussion}

\subsection{Initial Packing Analysis}

Distribution of CoCrMo particles in the initial packing structure of the composite plays a key role in the compaction and sintering steps, in order to consolidate the composite by powder metallurgy. Thus, the effect of adding CoCrMo particles in the initial packing was investigated by 3D images, acquired by computed microtomography. The 2D virtual slices of samples with different volume fractions (10-30\%) of CoCrMo particles are shown in Figure 2.

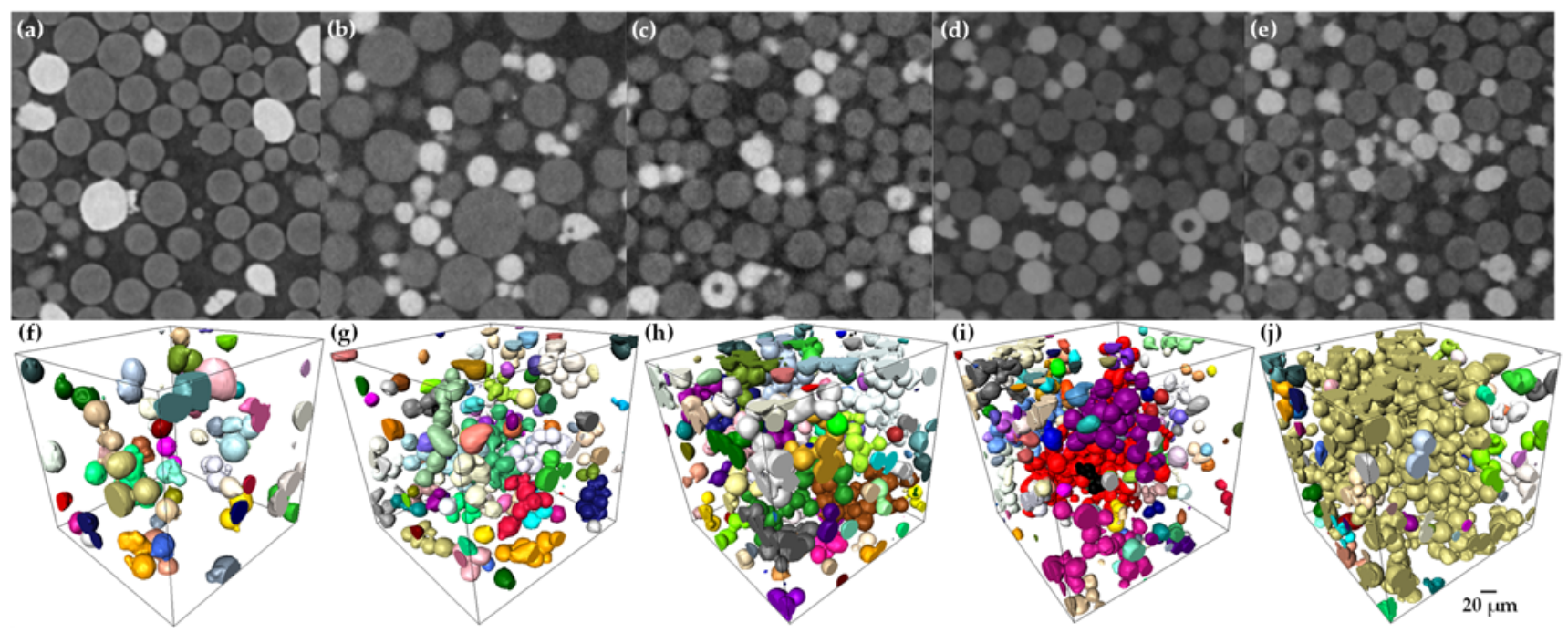

Figure 2. Two-dimensional virtual slices and $3 \mathrm{D}$ rendering of the CoCrMo particles of samples with different volume fractions of CoCrMo particles: (a,f) 10\%, (b,g) 15\%, (c,h) $20 \%,(\mathbf{d}, \mathbf{i}) 25 \%$ and $(\mathbf{e}, \mathbf{j}) 30 \%$.

In the images, the light gray particles are the CoCrMo particles, and the gray ones are the Ti6Al4V, which were identified by the absorption coefficient of the X-rays used in the microtomography technique. Moreover, the formation of a limited number of CoCrMo particles clusters was observed for samples containing 15 vol. $\%$ and beyond. In order to obtain quantitative data in 3D, the images were converted into binary images as described above, following the methodology proposed by Olmos et al. [20]. After image thresholding, 
the CoCrMo particles from the whole volume were separated from the Ti6Al4V, and a 3D rendering illustrates the distribution of such particles inside the 3D packing (Figure 2f-j). A color code was used to show the connectivity between CoCrMo particles. If the particles have the same color, this means that they are in contact, forming a cluster. From these images, it was qualitatively observed that as the vol.\% of the CoCrMo particles increases the formation of clusters increases too, as well as the size of clusters. The sample with 30 vol.\% of CoCrMo particles shows that most particles are interconnected, since one color is predominant in the image (Figure $2 \mathrm{j}$ ).

To determine the particle interconnectivity quantitatively, the following process was applied: First, the CoCrMo particles in the 3D images were set with an intensity of 255 and the Ti6Al4V and pores with zero. Second, we labeled all the objects contained in the image, and we obtained a new volume in order to identify every object in the image with a different gray value. Third, the volume of each object in the image was estimated, and each volume was considered a cluster of particles. Finally, the largest object inside the volume was the one that presented the largest interconnectivity. Thus, the volume of this object was divided by the total volume corresponding to the CoCrMo particles. This value is the connectivity between CoCrMo particles, and it is listed in Table 1 . The value of the volume fraction occupied by the CoCrMo particles, measured from the $3 \mathrm{D}$ images, relative to the solid volume is also listed in Table 1 . The obtained values of volume fraction of the CoCrMo particles are close to the theoretical ones estimated by the Rule of Mixtures. It was found that CoCrMo particles' connectivity decreases as the volume fraction increases from 10 to $20 \%$. This result is contrary to the one expected. However, it can be explained by the fact that first the CoCrMo particles formed small clusters between them. Then, these clusters began to get in contact between them, forming fewer yet bigger clusters. As a consequence, the connectivity between CoCrMo particles increases when the volume fraction increases to $25 \%$ and $30 \%$. The highest value of connectivity $(79.7 \%)$ for the Ti6Al4V /30CoCrMo sample indicates that most of the particles are forming a continuous network inside the packing. This could lead to the percolation of the CoCrMo particles, which according to Bouvard and Lange [21] is defined as a continuous cluster that touches both walls of the container. Percolation was only obtained for the sample with the largest connectivity, which shows a percolation system of particles in the three main directions of the volume analyzed and corresponds to a volume fraction of CoCrMo particles of $31 \%$. To corroborate this behavior, the ratio of the number of clusters $\left(\mathrm{N}_{\mathrm{c}}\right)$ by the total number of particles $\left(\mathrm{N}_{\mathrm{p}}\right)$ in the volume analyzed was calculated and listed in Table $1\left(\mathrm{~N}_{\mathrm{c}} / \mathrm{N}_{\mathrm{p}}\right)$. A value of one indicates that all the particles are isolated and as the value tends to be zero, this means that all particles are forming one unique cluster. As it was expected, the $\mathrm{N}_{\mathrm{c}} / \mathrm{N}_{\mathrm{p}}$ value decreases as the volume fraction of the CoCrMo particles increases, which confirms the formation of small clusters that increase their size by connecting between them until a larger cluster is formed to achieve percolation, as it was discussed above. The measured value for percolation (31\%) is similar to the one predicted by the numerical simulations (32\% volume of inclusions) for the same size ratio of particles [21,22] and the one experimentally established by Lange et al. (30\%) for compaction [23] and by Olmos et al. (31\%) for sintering [24].

Table 1. Quantitative data of the distribution of CoCrMo particles in the initial packing.

\begin{tabular}{cccc}
\hline Sample & $\begin{array}{c}\text { CoCrMo Volume } \\
\text { Fraction (Relative to } \\
\text { Solid Volume) }\end{array}$ & $\begin{array}{c}\text { CoCrMo Particles } \\
\text { Connectivity (\%) }\end{array}$ & ${\text { CoCrMo } \mathbf{N}_{\mathbf{c}} / \mathbf{N}_{\mathbf{p}}}$ \\
\hline Ti6Al4V/10CoCrMo & 0.11 & 16 & 0.673 \\
Ti6Al4V/15CoCrMo & 0.14 & 11 & 0.423 \\
Ti6Al4V/20CoCrMo & 0.19 & 8.5 & 0.363 \\
Ti6Al4V/25CoCrMo & 0.24 & 49.5 & 0.271 \\
Ti6Al4V/30CoCrMo & 0.31 & 79.7 & 0.166 \\
\hline
\end{tabular}


In order to determine the coordination number $(Z)$ of particles, the watershed segmentation method to separate the particles into individual objects in the images was performed. For more details of the methodology, see Vagnon et al. [25]. The watershed segmentation was applied to three different binary images, the first one containing only the Ti6Al4V particles, the second one the CoCrMo particles and the third one containing all particles. These images allow us to calculate the $\mathrm{Z}$ for the three different kinds of contacts detected in the binary mixture, matrix-matrix particles (Ti-Ti contacts), the inclusion-inclusion particles (Co-Co contacts) and the matrix-inclusion particles (Ti-Co contacts), respectively. The average value is computed for the three types of contacts $\left(Z_{\text {average }}\right)$, and these values are plotted as a function of the volume fraction (relative to the solid volume) of CoCrMo particles in the powder mixtures. It was observed that Ti-Ti contacts decrease as the volume fraction of CoCrMo increases, which is expected. In the same way, the $Z_{\text {average }}$ for the $\mathrm{Co}-\mathrm{Co}$ and Ti-Co contacts increases as the quantity of CoCrMo particles increases. The $\mathrm{Z}_{\text {average }}$ of $\mathrm{Co}-\mathrm{Co}$ contacts increases from 0.92 to a maximum value of 2.82 for the highest volume fraction of CoCrMo particles, where percolation was found. This value is the same as the one predicted by numerical simulations at the percolation threshold 2.8 [21]. The $Z_{\text {average }}$ of the Ti-Co goes from 0.38 up to 2.36. It was observed that a higher increment in the Ti-Co contacts is obtained when the volume fraction of the CoCrMo particles increases from 20 to $25 \%$. This increment matches with the higher decrement in the Ti-Ti contacts for the same range of CoCrMo particles (Figure 3).

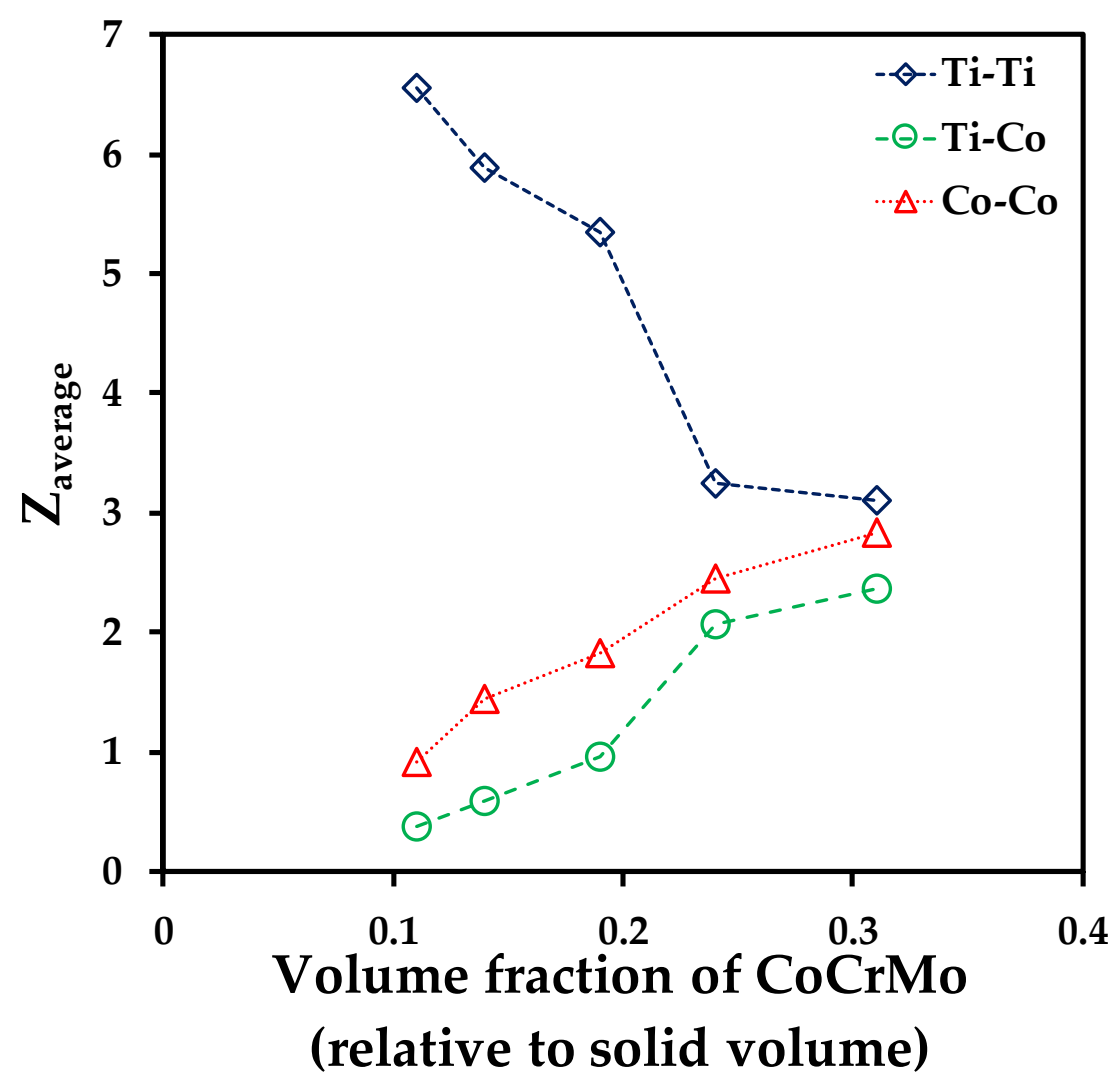

Figure 3. Coordination number of the different kinds of contacts between the powder mixtures as a function of the volume fraction of the CoCrMo particles.

\subsection{Compressibility of Mixtures}

The compaction behavior of Ti6Al4V powders and Ti6Al4V/xCoCrMo mixtures up to $450 \mathrm{MPa}$ is shown in Figure 4a. Initially, the relative density of Ti6Al4V was around $63 \%$, and similar values were found when the CoCrMo vol. $\%$ was added (values around $62-63 \%$, see Table 2). For comparison purposes, a compact of CoCrMo particles was fabricated and the packing relative density found was $62 \%$. This suggests that the addition of particles 
with similar shape and size distribution has no effect on the initial packing. Two of the three stages, suggested in the model of three-stages proposed to drive the densification process of spherical powders during compaction, can be identified from Figure 4a: rearrangement and plastic deformation of particles $[26,27]$.
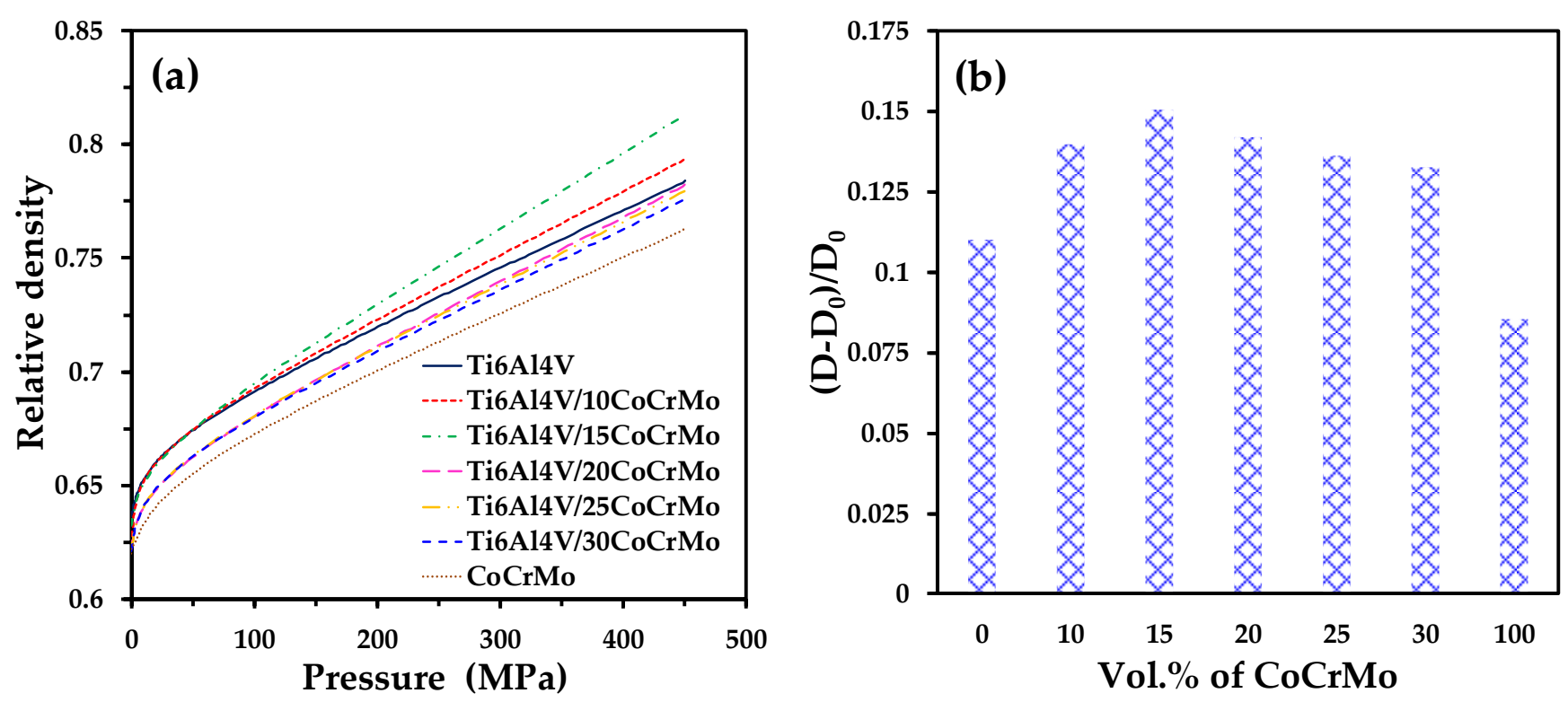

Figure 4. Compressibility of powder mixtures in close die pressing: (a) evolution of relative density as a function of applied pressure and $(\mathbf{b})$ densification $\left(\left(\mathrm{D}-\mathrm{D}_{0}\right) / \mathrm{D}_{0}\right)$ obtained by compaction.

Table 2. Density-pressure liner curve fitting parameters for Ti6Al4V and composite samples.

\begin{tabular}{cccccc}
\hline Sample & $\mathbf{A}_{\mathbf{1}}$ & $\mathbf{A}_{\mathbf{2}}$ & $\mathbf{B}$ & $\mathbf{D}_{\mathbf{0}}$ & $\mathbf{D}_{\mathbf{c}}$ \\
\hline Ti6Al4V & 0.018 & 0.036 & 1.011 & 0.636 & 0.715 \\
Ti6Al4V/10CoCrMo & 0.019 & 0.040 & 0.977 & 0.623 & 0.735 \\
Ti6Al4V/15CoCrMo & 0.020 & 0.053 & 0.999 & 0.632 & 0.744 \\
Ti6Al4V/20CoCrMo & 0.018 & 0.039 & 0.973 & 0.622 & 0.725 \\
Ti6Al4V /25CoCrMo & 0.018 & 0.038 & 0.970 & 0.621 & 0.719 \\
Ti6Al4V/30CoCrMo & 0.018 & 0.037 & 0.972 & 0.622 & 0.717 \\
CoCrMo & 0.016 & 0.030 & 0.967 & 0.620 & 0.678 \\
\hline
\end{tabular}

At low stress that has not exceeded $20 \mathrm{MPa}$, densification is due to particle rearrangement. Densification shows similar behavior for Ti6Al4V and composites with up to 15 vol.\% of CoCrMo particles. However, lower densification was reached for samples with a higher volume fraction of CoCrMo particles. This may be due to the effect of the surface roughness of particles that reduces the rearrangement. As can be observed in Figure 5a, the roughness of the CoCrMo particles seems to be higher than that of the Ti6Al4V particles. For values of stress over $20 \mathrm{MPa}$, densification is mainly due to plastic deformation of the particles and it can be observed that all the samples present the same compression behavior. As a consequence of both densification mechanisms, the highest final green density was attained for the fraction of CoCrMo of $15 \mathrm{vol} . \%$. Thus, for the maximum pressure applied of $450 \mathrm{MPa}$, higher additions than $15 \mathrm{vol} . \%$ of CoCrMo particles reduced the green relative density, the composite with $30 \mathrm{vol} . \%$ presenting the lowest value. It is also observed that the lowest green relative density is obtained when only CoCrMo is used. Finally, the maximal relative density reached was $81 \%$, and after elastic recovery, it decreased at $74 \%$ for the composite with 15 vol. $\%$ of CoCrMo. 

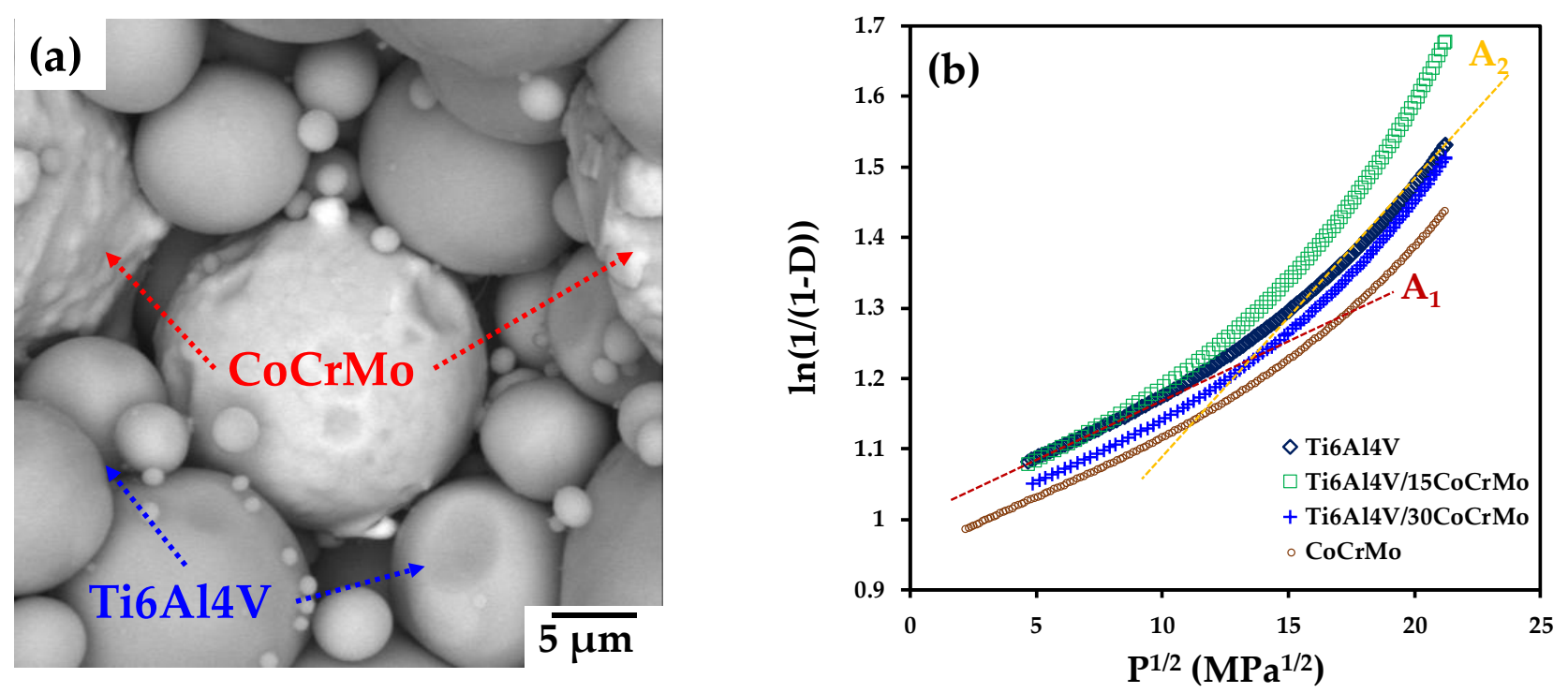

Figure 5. (a) SEM micrograph of fractured Ti6Al4V /15CoCrMo sample after compaction and (b) Panelli-Filho model for compressibility under cold compaction.

Densification $\left(\left(D-D_{0}\right) / D_{0}\right)$ is a parameter that gives qualitative information about the powder mixtures' compressibility, and it is shown in Figure $4 \mathrm{~b}$ as a function of the quantity of CoCrMo particles added. The addition of CoCrMo particles enhanced the densification of mixtures with respect to that obtained for the Ti6Al4V powders, with a maximum value when $15 \mathrm{vol} . \%$ is added. After that, a reduction in densification was obtained up to $30 \mathrm{vol} . \%$. Moreover, the minimum value of densification for composites is significantly higher than the densification obtained for the sample with only CoCrMo. When the densification is increasing, the mechanism behind it may reside in the contact relation between $\mathrm{Ti}-\mathrm{Co}$ particles. The compressive strength of CoCrMo particles is greater compared to Ti6Al4V. This possibly generates a higher plastic deformation of the Ti6Al4V particles, as it appears in the fractured Ti6Al4V/15CoCrMo sample shown in Figure 5a. A closer look at the particles after compression, as pictured in the SEM micrograph in Figure 5a, allowed us to detect that the Ti6Al4V particles suffer a larger deformation on the contact area with $\mathrm{CoCrMo}$, which could confirm that the contacts between matrix and reinforcing particles enhance deformation of softer particles. The mechanism for the reduction in densification may reside in the formation of a percolation network of CoCrMo particles, as formed for the 30 vol.\% sample (as evident in the 3D rendering shown in Figure 2j). When the formation of a percolation network of CoCrMo particles occurs, the network supports the applied load instead of the Ti6Al4V matrix, changing the densification mechanism as it was reported by Bouvard and Lange [21].

The compressibility behavior was analyzed using the equation proposed by Panelli and Filho [28], which has shown good agreement with the compaction of different metals:

$$
\ln \left(\frac{1}{1-\mathrm{D}}\right)=\mathrm{A} \sqrt{\mathrm{P}}+\mathrm{B}
$$

where A and B are characteristic constants of the powder [29]. The value of A gives the plastic deformation capacity of powders during compaction. Therefore, as the A value increases the plastic deformation increases too. Meanwhile, the B value indicates the initial packing conditions before applying the pressure. Figure $5 b$ shows the left part of Equation (4) as a function of the square root of the applied pressure during compaction. For better observation, only four curves are presented, corresponding to samples with $0,15,30$ and 100 vol.\% of CoCrMo particles. As can be observed in Figure 5b, it is not convenient to realize a unique linear regression of the curves, as it would generate inaccuracy. In consequence, two main regressions were estimated for the samples, named $A_{1}$ and $A_{2}$. 
The values of the constants $A_{1}$ and $A_{2}$ for all the samples are listed in Table 2. $A_{1}$ was fitted for values of pressure between 20 and $150 \mathrm{MPa}$. These values correspond to the end of rearrangement and the break point to the linear regression. For this interval of pressure, the values of $A_{1}$ are very close to each other, which indicates that at lower pressure a small deformation is induced no matter what kind of contact is transmitting the load. Furthermore, the value of $\mathrm{A}_{2}$ for the Ti6Al4V sample is similar to that reported by Chen et al. for Ti6Al4V powders with irregular shape obtained by mechanical milling (0.045-0.034) [27]. In conclusion, this validates the use of the Panelli and Filho model (Equation (4)) for composites in order to obtain the plastic behavior. For the composite samples, it was found that as the pressure is higher than $150 \mathrm{MPa}$, the value of the $\mathrm{A}_{2}$ increases up to 15 vol.\% of CoCrMo particles, and then it decreases. The $A_{2}$ value for such samples is $47 \%$ higher than that of the sample without CoCrMo, which indicates that compressibility was improved. This is associated with the deformation reached at the Ti-Co contacts that allows for more indentation. Therefore, larger deformation was obtained. In contrast, for 20 vol. $\%$ or above of CoCrMo particles, a reduction in the $\mathrm{A}_{2}$ value was obtained, which is due to the increment of $\mathrm{Co}-\mathrm{Co}$ contacts that possibly reach a percolation network that supports most of the pressure, as it was discussed above. This can be supported by the fact that the $\mathrm{Z}_{\text {average }}$ of $\mathrm{Co}-\mathrm{Co}$ contacts for the initial packing of samples with 20 vol.\% of CoCrMo and above is higher than two, a value close to the critical value for percolation proposed by Bouvard et Lange (2.8) [21]. It can also be noticed that as the volume fraction of CoCrMo increases up to $20 \%$ the compression behavior is more similar to the one obtained for the CoCrMo sample. The value of $\mathrm{B}$ is around one for all samples, which indicates that initial packing is almost the same for all samples. This is mainly because the shape and particle size distribution are similar for both kind of powders, which allows the obtainment of more or less the same tap density. The final relative density after unloading $\left(D_{c}\right)$ is listed in Table 2, where it is possible to notice that a higher value was obtained for the sample with 15 vol.\% of CoCrMo particles, which shows better compressibility, according to Panelli and Filho [28].

\subsection{Sintering Analysis}

The relative density was estimated during the whole sintering thermal cycle by using Equations (1) and (3), in which the instantaneous volume depends on the densification during sintering and can be estimated from the dilatometry data. As the radial displacement cannot be directly measured from dilatometry, it was assumed that it follows the same variation as the measured axial displacement, with the final axial to radial shrinkage ratio as a corrective factor. Thus, the instantaneous volume can be obtained from:

$$
\mathrm{V}_{\mathrm{i}}=\left(\Delta \mathrm{l}+\mathrm{l}_{\mathrm{o}}\right)\left(\Delta \mathrm{d}+\mathrm{d}_{\mathrm{o}}\right)^{2}\left(\frac{\pi}{4}\right)
$$

The evolution of the relative density of pure Ti6Al4V and composites was plotted as a function of temperature in Figure 6a. 

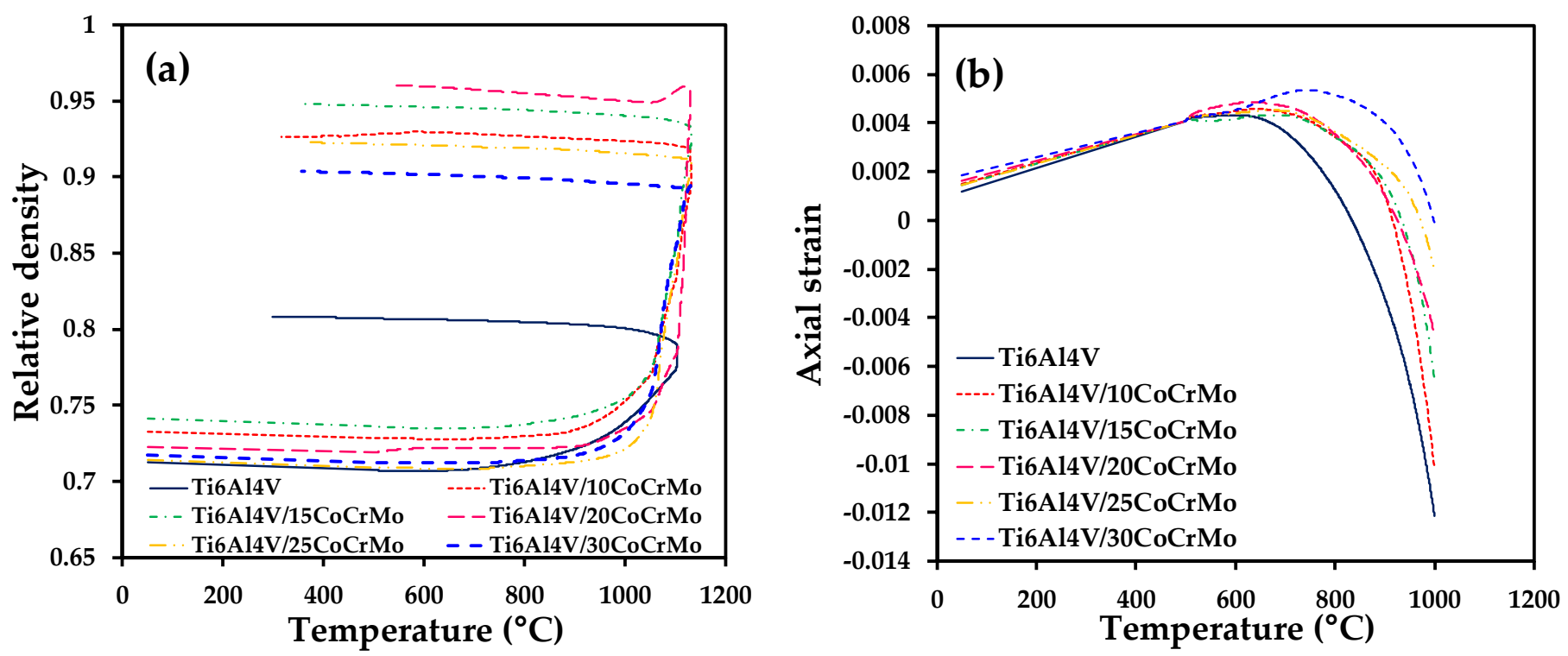

Figure 6. (a) Evolution of the relative density during the sintering cycle and (b) axial strain of samples versus temperature.

The initial relative density is different for each sample, as the mixture's compressibility depends on the CoCrMo content. All the samples showed a decrease in the relative density during heating, which is due to thermal expansion. Then, the relative density increased for all samples. The Ti6Al4V sample starts densification at $670^{\circ} \mathrm{C}$. Meanwhile, the addition of CoCrMo particles generates a delay of the sintering activation for composites, as densification begins at around $840^{\circ} \mathrm{C}$. For example, Figure $6 \mathrm{~b}$ offers a better image of the effect of CoCrMo particles addition on the onset of sintering, in which the axial strain was depicted as a function of the temperature up to $1000^{\circ} \mathrm{C}$. This particular temperature was chosen because solid-state sintering is achieved below such temperature, according to the Ti-Co phase diagram that indicates $1020^{\circ} \mathrm{C}$ for the eutectic reaction [30] that axial strain decreases as the vol.\% of CoCrMo particles increases. This is associated with the reduction of Ti-Ti contacts, as it was demonstrated in Figure 3, since the first stage of sintering is due to solid-state sintering of the matrix.

Then, as the temperature continues to increase, the Ti6Al4V relative density enhances. However, relative density reached a maximum value of $80 \%$ after the sintering cycle. On the contrary, the sintering of composites starts later but is highly accelerated at around $950{ }^{\circ} \mathrm{C}$, with a drastic change in sintered relative density over a narrow temperature range, which is also a characteristic of supersolidus liquid-phase sintering [14]. After that, composite samples continue to densify until the sintering temperature is reached. During cooling, an additional densification was obtained due to thermal contraction. After sintering, the relative density of composites is higher than $90 \%$; the highest value of $96 \%$ was obtained for the Ti6Al4V/20CoCrMo sample. This is in spite of the fact that the highest green density was obtained for the sample with 15 vol. $\%$ of CoCrMo after powder compression.

The instantaneous densification rate $\dot{\mathrm{D}}$ can be estimated as follows [31]:

$$
\dot{\mathrm{D}}=\frac{\mathrm{dD}_{\mathrm{i}}}{\mathrm{dt}_{\mathrm{i}}}=\frac{\mathrm{D}_{\mathrm{i}}-\mathrm{D}_{\mathrm{i}-1}}{\mathrm{t}_{\mathrm{i}}-\mathrm{t}_{\mathrm{i}-1}}
$$

where $D_{i}$ is the instantaneous relative density at time $t_{i}(s)$, for an interval of $t_{i}-t_{i-1}$ of $3 s$. It was found that the densification rate is largely increased by the addition of CoCrMo particles (see Figure 7). Consequently, this increment can be up to five times larger for the samples with 20 vol. $\%$ of CoCrMo and above, with respect to the sample without CoCrMo (Figure 7). Thus, most typically, this densification rate is due to the formation of eutectic liquid that fills the pores and densifies the samples. 


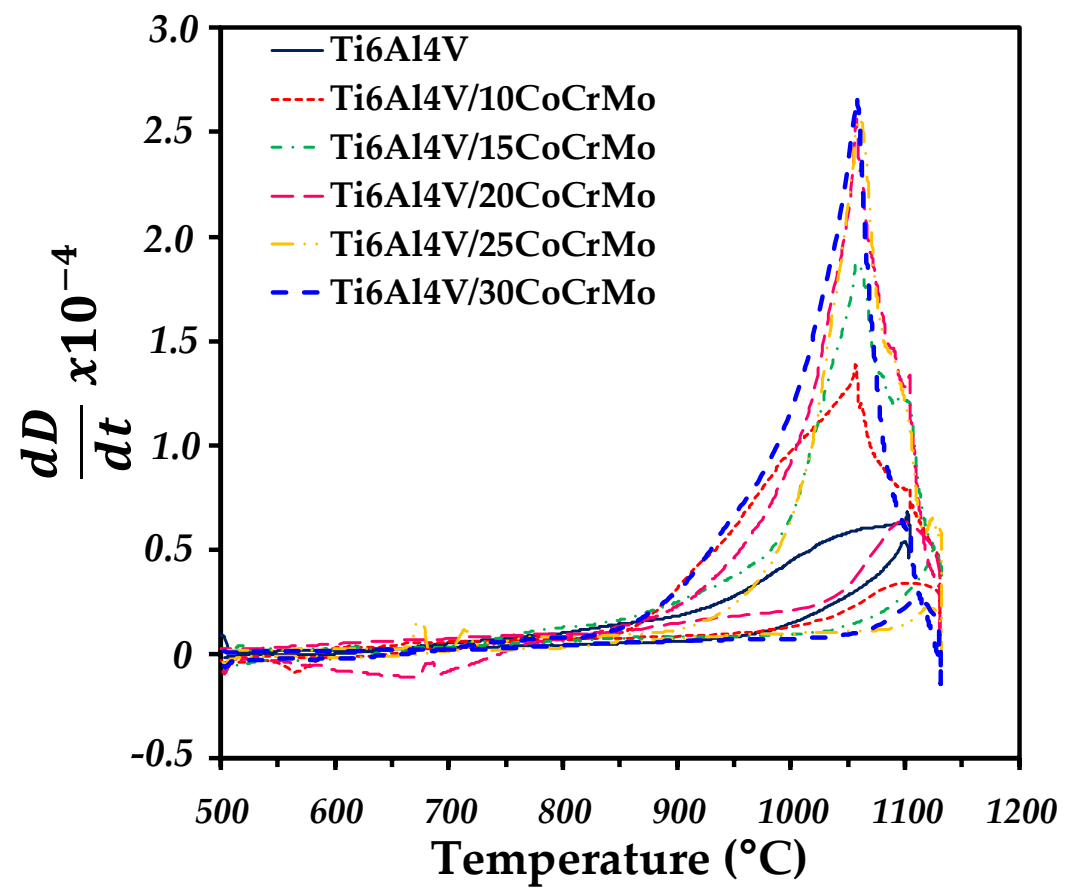

Figure 7. Densification rate as a function of temperature for all the samples.

Furthermore, it was estimated that densification rate undergoes a sharp increment around $950{ }^{\circ} \mathrm{C}$, a temperature $70{ }^{\circ} \mathrm{C}$ lower than indicated by the Ti-Co binary phase diagram. In the function of the temperature, first the eutectic reaction might generate an indentation at the Ti-Co contacts that induces densification of the sample. Then, as the temperature increases, eventually the liquid is formed at the surface of particles and the viscosity is reduced until the liquid is able to spread in the interconnected porosity, as it was reported by Mihalcea et al. [19]. Finally, this occurs at a critical temperature of $1060{ }^{\circ} \mathrm{C}$, leading to the highest value of densification rate for the composites.

Samples were sintered at a maximum temperature of $1130{ }^{\circ} \mathrm{C}$, as sintering above the critical temperature leads to compact distortion as the liquid drops at the bottom of the compact by gravity. The sharp increment in sintered density over a narrow temperature range and the existence of a wetting liquid that spreads to the particle contacts and enhances densification are similar to supersolidus sintering, with the difference that in SLPS the liquid forms inside the particles, and in this case the liquid forms at the Ti-Co contacts [14].

\subsection{Microstructural Characterization}

\subsubsection{SEM Observation}

The lamellar $\alpha+\beta$ Ti microstructure was found in the sample without reinforcing particles (Figure 8a), in which it was possible to identify that the sintering was in the early stage, as the spherical shape of the particles and interparticle pores all over the surface were clearly observed. The addition of $\mathrm{CoCrMo}$ particles induces a different microstructure in composites even for 10 vol.\%. Two main phases can be distinguished in Figure $8 \mathrm{~b}-\mathrm{f}$. The first one corresponds to $\alpha$-Ti in the matrix of the composite, in which the lamellar microstructure of $\beta$-Ti is no longer observed. This $\alpha$-Ti phase is surrounded by a Ti-Co eutectic phase that corresponds to the second phase detected. For example, the composite with 10 vol.\% of CoCrMo particles pictured in Figure 8b exhibited an incipient $\mathrm{Ti}-\mathrm{Co}$ phase covering the surface of the Ti6Al4V particles. Moreover, the spherical shape of the initial particles is no longer observed as the Ti-Co reaction already started at the surface of particles. As the CoCrMo volume fraction increases, the thickness of the eutectic phase increases too, and as the liquid in the system increments, a similar thickening has been reported for supersolidus sintering $[14,32]$. 


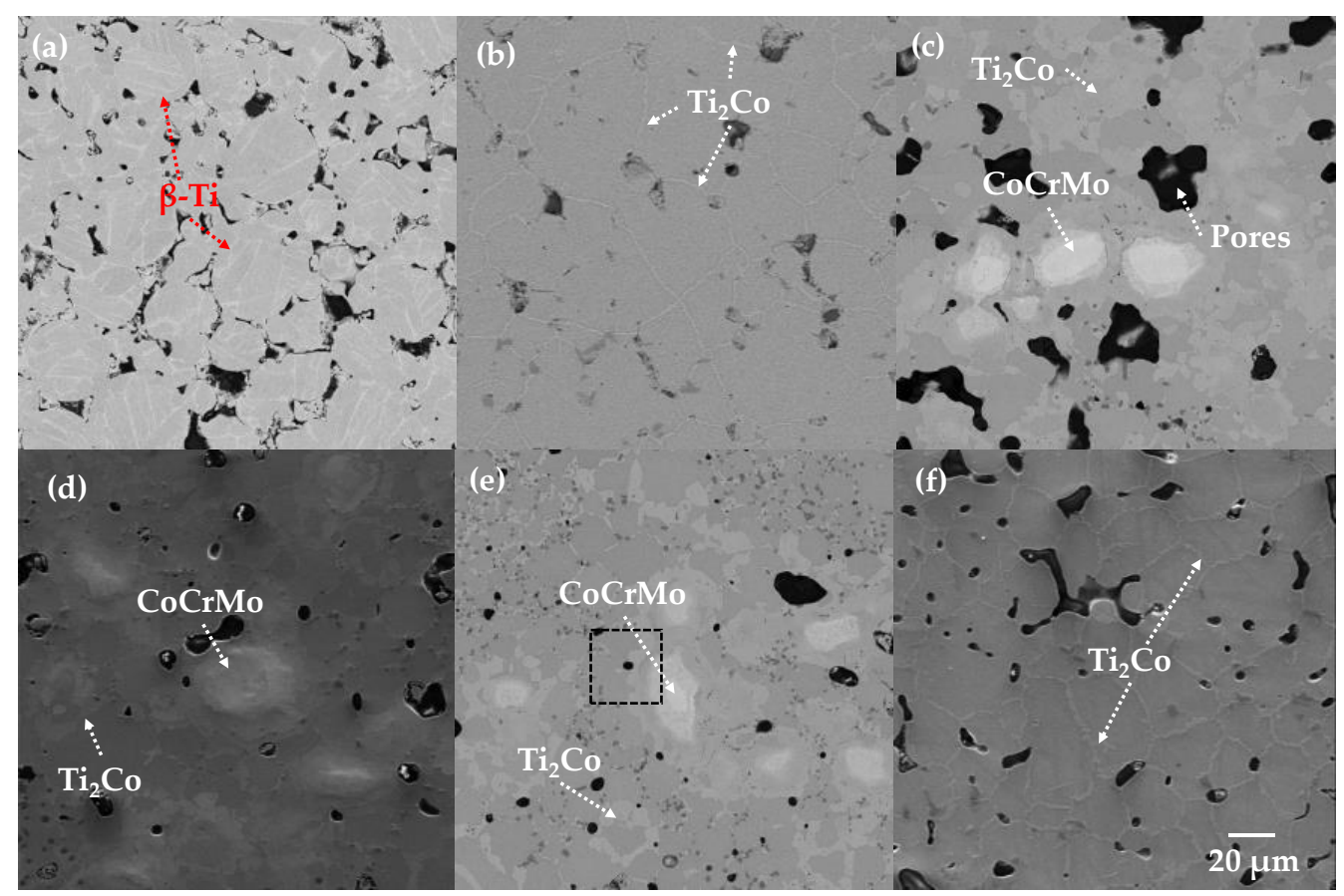

Figure 8. SEM BSE (back-scattered electron) micrographs of the (a) Ti6Al4V and composites with different vol.\% of CoCrMo particles: (b) 10, (c) 15, (d) 20, (e) 25 and (f) 30.

Furthermore, it is possible to observe a few remaining CoCrMo particles in the composite, after sintering in samples with 15, 20 and 25 vol.\% of CoCrMo. This allows the observation that $\mathrm{CoCrMo}$ particles diffuse into the liquid phase and the diffusing process starts at the surface of particles, in order to form the eutectic that fills the interparticle porosity around the matrix particles. The global porosity is reduced in comparison to the Ti6Al4V sample. Nonetheless, some large pores can be detected in composite samples. We assume that such pores might be formed during the dissolution of CoCrMo particles, because their size comes close to the size of such particles. Besides, pores have a rounded shape, and they seem to be isolated from each other, as illustrated by Figure 8e. Finally, it can also be noticed from SEM images that the sample with 20 vol.\% of CoCrMo shows the lower porosity, which confirms the higher value of relative density.

Subsequently, images taken at higher magnification are shown in Figure 9, a zoom-in on the area defined by the black rectangle in Figure 8e. Consequently, CoCrMo particles not fully dissolved into the matrix can be observed, as well as the eutectic phase, which fills the porosity left between Ti6Al4V particles (Figure 9a). It can also be observed that eutectic liquid is formed by layers, which confirms that the liquid is formed at the surface of particles and so is different from either supersolidus sintering or conventional liquidphase sintering. In order to determine the composition of the different phases observed in Figure 9 qualitatively, an EDS analysis was performed in spot mode, as indicated with a cross in Figure 9b. Point number one indicates that Co content in CoCrMo particles diffuses to form the eutectic liquid and the Mo is the last element to be dissolved in the eutectic liquid, according to the atomic \% of each element listed in Table 3. Point number two is located at the eutectic phase, which confirms that the main phase is the $\mathrm{Ti}_{2} \mathrm{Co}$. Although, it was observed that $\mathrm{Al}, \mathrm{V}, \mathrm{Cr}$ and $\mathrm{Mo}$ are present in the liquid. Point number three is placed at the matrix and it was found to be more or less the composition of the Ti6Al4V alloy, as it presents an increment in the Al content, which is a stabilizer of the $\alpha$-Ti phase. This can explain why the $\beta$-Ti phase is no longer observed in composite samples. From SEM images, it was also possible to observe the formation of some intermetallics consisting of a combination of different elements such as $\mathrm{Al}, \mathrm{V}, \mathrm{Ti}$ and $\mathrm{Co}$, according to the element analysis of point number four (see Table 3). However, precipitates formation seems to take place at the boundaries of the eutectic phase, but the mechanism is not well understood 
(Figure 9c). Figure 9d-g shows the distribution of the eutectic liquid around Ti6Al4V particles by EDS mapping analysis, which confirms that the liquid is mainly formed by Ti and Co.
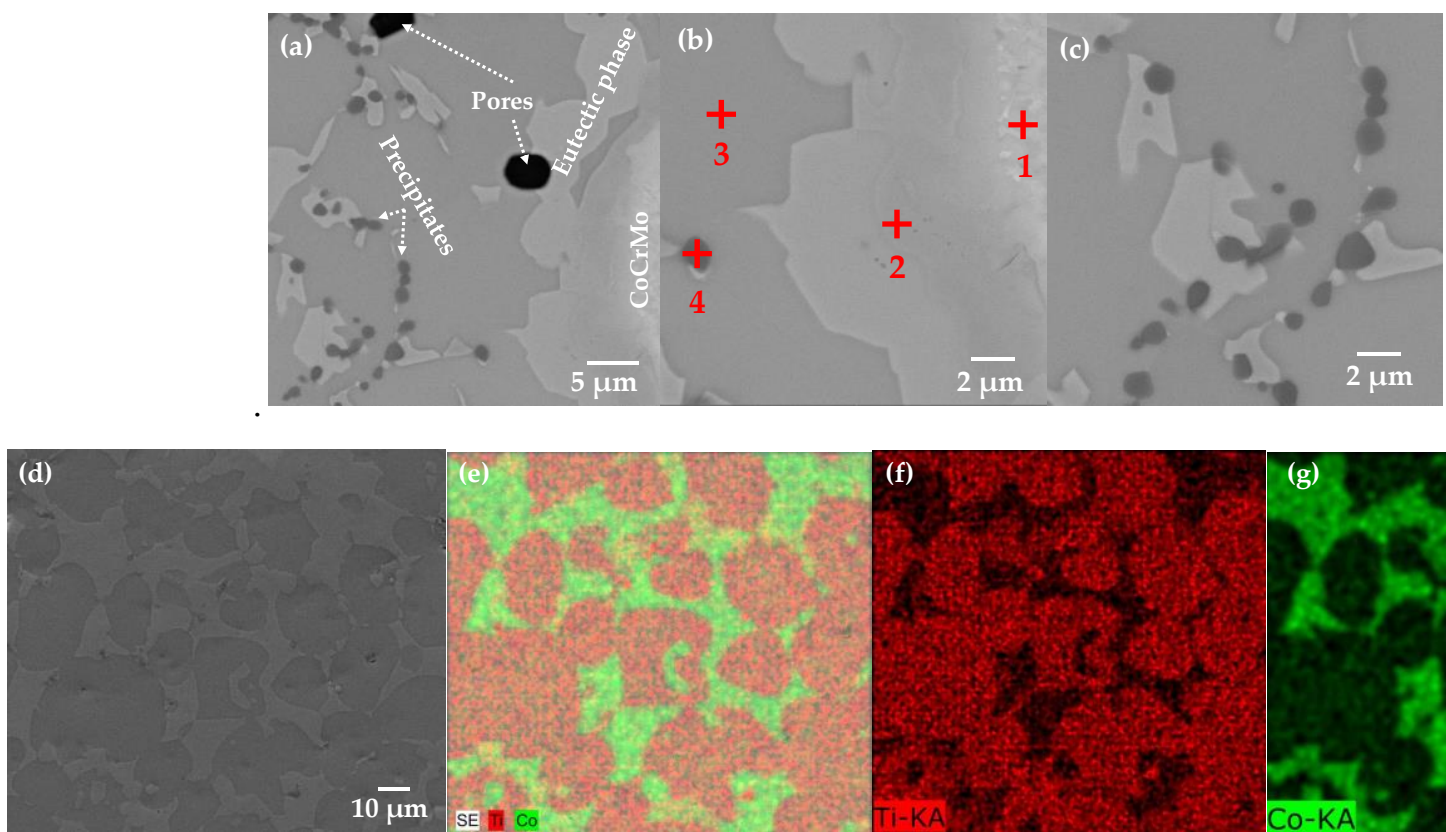

\section{(f)}

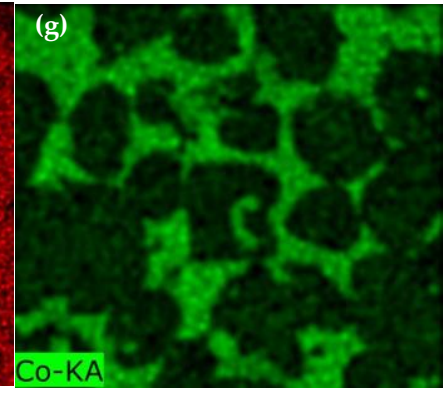

Figure 9. SEM BSE (back-scattered electron) micrographs of the sample containing 25 vol.\% of CoCrMo: (a) area of black rectangle in Figure 7e; (b) interphase between a CoCrMo particle and Ti6Al4V; (c) precipitates at the boundaries of the eutectic phase. (d-g) are EDS elemental mapping of the composite containing $20 \%$ of CoCrMo particles.

Table 3. EDS results of spot mode in Ti6Al4V-25 vol.\% of CoCrMo sample after sintering.

\begin{tabular}{|c|c|c|c|c|c|c|c|}
\hline \multirow{2}{*}{ Point Analysis } & \multicolumn{6}{|c|}{ At. $\%$ of Elements } & \multirow[t]{2}{*}{ Possible Phases } \\
\hline & $\mathrm{Ti}$ & Al & $\mathbf{V}$ & Co & $\mathrm{Cr}$ & Mo & \\
\hline $\begin{array}{l}\text { Point } 1 \text { in } \\
\text { Figure } 9 b\end{array}$ & 27.19 & 1.43 & 0.5 & 17.07 & 9.24 & 44.56 & $\mathrm{Mo}, \mathrm{Ti}_{2} \mathrm{Co}$ \\
\hline $\begin{array}{l}\text { Point } 2 \text { in } \\
\text { Figure } 9 b\end{array}$ & 57.77 & 4.41 & 0.59 & 31.31 & 5.61 & 0.27 & $\mathrm{Ti}_{2} \mathrm{Co}$ \\
\hline $\begin{array}{l}\text { Point } 3 \text { in } \\
\text { Figure } 9 b\end{array}$ & 72.73 & 7.61 & 2.04 & 9.27 & 7.15 & 1.19 & $\begin{array}{c}\text { Ti6Al4V matrix } \\
\alpha-\mathrm{Ti}\end{array}$ \\
\hline $\begin{array}{l}\text { Point } 4 \text { in } \\
\text { Figure } 9 b\end{array}$ & 78.87 & 3.31 & 1.24 & 16.58 & - & - & Intermetallics \\
\hline
\end{tabular}

\subsubsection{X-ray Diffraction Analysis}

The main peaks corresponding to the phases present in the initial powders of Ti6Al4V and CoCrMo are shown in Figure 10. For the Ti6Al4V, the hexagonal $\alpha$-Ti peaks and only the main peak corresponding to the cubic $\beta$-Ti are detected, which indicates that the initial powders have the $\alpha+\beta$ microstructure. For the $\mathrm{CoCrMo}$, the main peaks of the FCC $\mathrm{CoCr}$ microstructure are obtained as it was reported for these alloys [33]. The X-ray patterns for the composites with different quantities of CoCrMo are also plotted in Figure 10. For 10 and 15 vol.\%, a bimodal microstructure composed of $\alpha$-Ti and the $\mathrm{Ti}_{2}$ Co phases was found. The main peaks of $\mathrm{Ti}_{2} \mathrm{Co}$ have been reported elsewhere for Ti-Co systems [34,35]. When the addition of $\mathrm{CoCrMo}$ is higher than $20 \mathrm{vol} . \%$, three different phases can be detected from the peaks in the X-ray patterns: $\alpha-\mathrm{Ti}_{1} \mathrm{Ti}_{2} \mathrm{Co}$ and TiCo. Moreover, the formation of TiCo can be attributed to a lack of Ti in the eutectic phase, since the temperature of the formation of TiCo, according to the Ti-Co phase diagram, doesn't correspond to the sintering temperature 
used in our case [30]. The detection of additional phases corresponding to the precipitates observed in Figure $9 \mathrm{c}$ by X-ray diffraction was not possible, and this can be explained by the fact that the quantity was too small to be detected. However, the shape and distribution of similar precipitates have been observed by Wang and Welsch in Ti-Co melting alloy, and they attributed this to the intermetallics of TixCo [5].

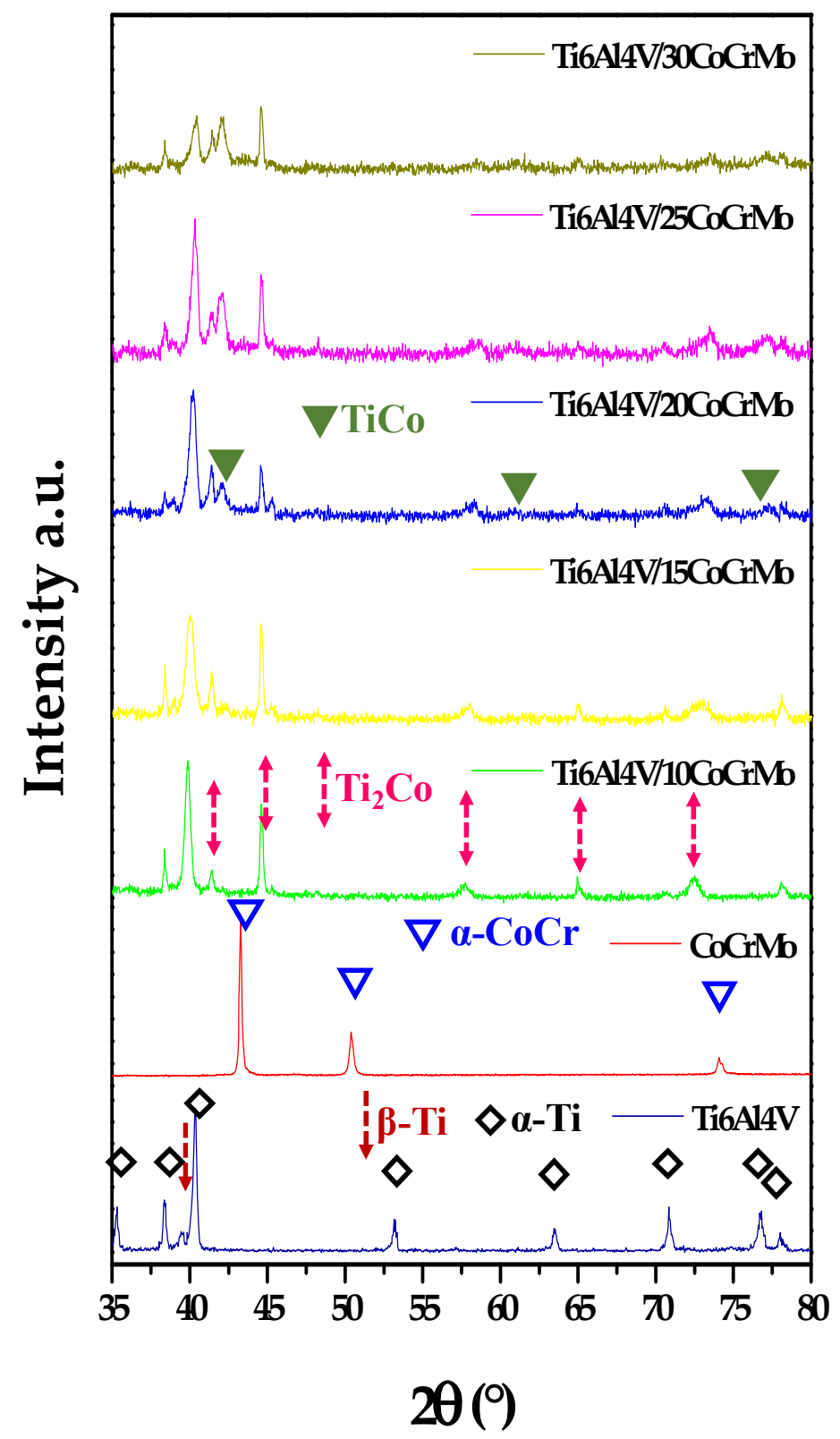

Figure 10. X-ray patterns of Ti6Al4V and CoCrMo powders before sintering and composite samples after sintering.

\subsection{Hardness}

In this work, the hardness of the composite increased up to $570 \mathrm{HV}$ as the volume fraction of CoCrMo was increased up to $20 \%$, and then, for higher quantities of CoCrMo, the average value decreased at $380 \mathrm{HV}$. The hardness of the composite is three times higher compared to that of Ti6Al4V sintered at the same conditions (see Figure 11) and also higher compared to that reported for Ti6Al4V sintered at higher temperatures, with values of $354-483 \mathrm{Hv}[36,37]$. 


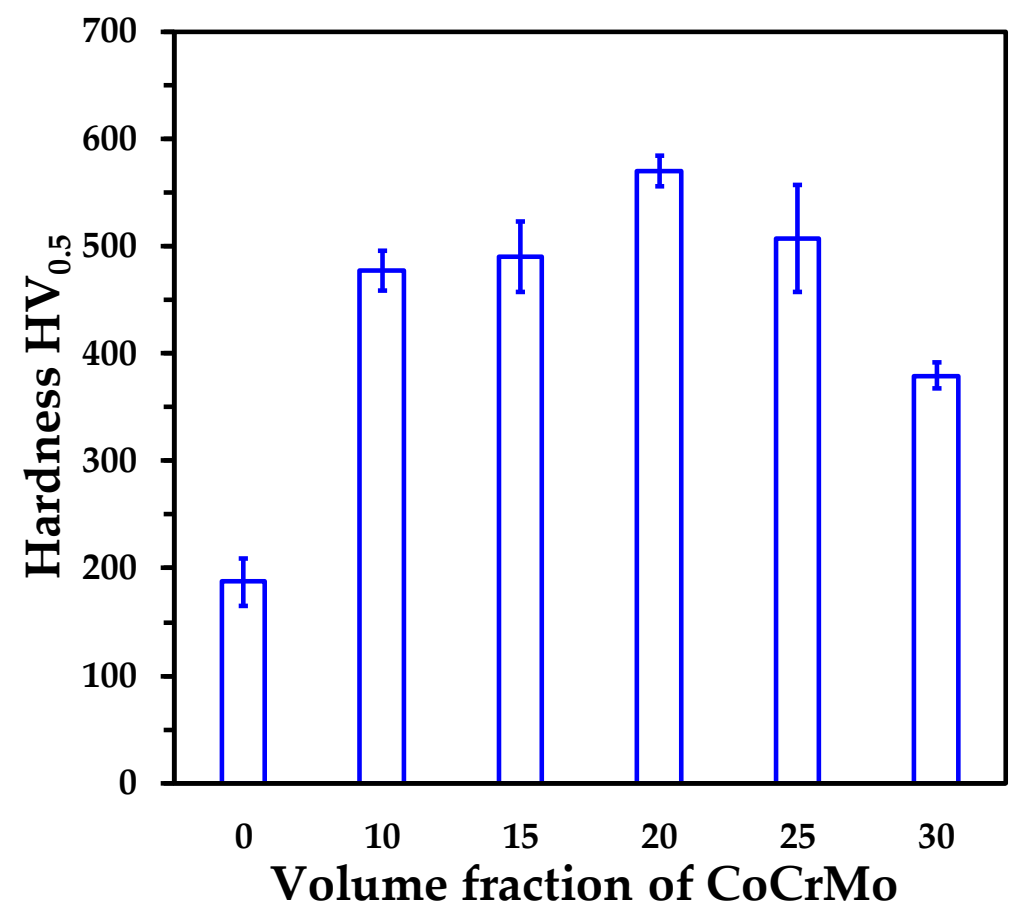

Figure 11. Average values of hardness for Ti6Al4V and composite samples sintered at $1130{ }^{\circ} \mathrm{C}$.

The values obtained are slightly higher than those reported for Ti-Co alloys fabricated by casting $(341-540 \mathrm{HV})[4,5]$. The increment of the hardness is associated with the good distribution of the eutectic phase, which shows higher values of hardness in comparison to the matrix of the Ti6Al4V. The maximum value of hardness obtained in this work ( $570 \mathrm{HV}$ ) is also higher than the those reported for the CoCrMo alloys fabricated by sintering at $1300{ }^{\circ} \mathrm{C}, 434 \mathrm{HV}$ [38] and by Laser engineered net shaping (LENS ${ }^{\mathrm{TM}}$ ), $361 \mathrm{HV}$ [39]. This could suggest that the Ti6Al4V / 20CoCrMo composite is a good candidate for applications such as dental implants and load bearing implants, since the CoCrMo alloy is used for such applications. Besides, the reduction in the quantity of $\mathrm{Co}$ in the composite can also reduce the release of $\mathrm{Co}$ and $\mathrm{Cr}$ ions, due to corrosion and the wear undergone in such applications. The release of $\mathrm{Co}$ and $\mathrm{Cr}$ ions has been identified as a problem, because they can generate cancer and negative physiological impacts [40]. On the other hand, mechanical strength and corrosion, as well as the wear properties, will be evaluated later to determine the feasibility of such composites for bone or dental implants.

\section{Conclusions}

A comprehensive microstructural, metallurgical and mechanical characterization was performed by computed microtomography, SEM, X-ray diffraction analysis and Vickers hardness tests on Ti6Al4V/xCoCrMo composites fabricated by powder metallurgy.

Percolation of CoCrMo particles within the powder mixture was found when $31 \mathrm{vol} . \%$ was added to the Ti6Al4V matrix, with respect to the solid fraction. The mechanism of percolation was the formation of small clusters that interconnect to form a larger one. Additionally, the critical value for the coordination number of Co-Co contacts was 2.8, which confirms the existing models for percolation of inclusions in a composite matrix.

Two mechanisms drive the compression behavior. First, densification is enhanced by the deformation undergone at the Ti-Co contacts. Second, once the percolation is reached, the densification of the compact is driven by the reinforcing particles.

The sintering of composites is achieved in two steps. The first one corresponds to the solid-state diffusion that helps to create a rigid skeleton between Ti6Al4V particles, since the formation of interparticle necks is carried on. The solid-state diffusion was affected by a reduction on the Zaverage of the Ti-Ti contacts as the volume fraction of CoCrMo 
increased. The second one is achieved by liquid state, which is formed at the Ti-Co contacts due the eutectic reaction. This stage achieved the highest densification of compacts.

The results showed that a $20 \mathrm{vol} . \%$ of CoCrMo particles provides the highest value of relative density after sintering and hardness, which would indicate higher mechanical proprieties and wear resistance than the Ti6Al4V and CoCrMo alloys, and so it is the optimum value for the Ti6Al4V/xCoCrMo composites. Thus, our findings on a novel biomaterial with enhanced durability can potentially benefit the production of load bearing implants.

Author Contributions: L.O.: conceptualization, methodology and validation; E.M.: investigation, formal analysis and writing-original draft preparation; H.V.-H.: resources, project administration and supervision; O.J.: writing-review and editing; J.C.: investigation; D.A.: software. All authors have read and agreed to the published version of the manuscript.

Funding: This research was funded by the National Council for Science and Technology CONACYT via Ph.D. Scholarship No. 473734 and Postdoctoral Research Grant No. 000614. The APC was funded by TecNM/Instituto Tecnológico de Morelia via Héctor Vergara-Hernández.

Institutional Review Board Statement: Not applicable.

Informed Consent Statement: Not applicable.

Data Availability Statement: The manuscript "Processing and characterization of bilayer materials by solid state sintering for orthopedic applications" is an original work and has not been sent elsewhere. All the results are part of the research of the doctoral student (E. Mihalcea). The experiments reported in this work focus on fabricating and characterizations of a novel composite. These data will be the basis for future works in the authors' field of research.

Acknowledgments: The authors would like to thank the CIC of the UMSNH and the National Laboratory SEDEAM-CONACYT for their financial support and for the facilities provided for the development of this study and to Laboratory "LUMIR" Geosciences of the UNAM, Juriquilla, for the 3D image acquisition and processing.

Conflicts of Interest: The authors declare that they have no conflict of interest.

\section{References}

1. Wang, R.R.; Fenton, A. Titanium for prosthodontic applications: A review of the literature. Quintessence Int. 1996, 27, 401-408.

2. Park, Y.; Butt, D.P. Composition dependence of the kinetics and mechanisms of thermal oxidation of titanium-tantalum alloys. Oxid. Met. 1999, 51, 383-402. [CrossRef]

3. Liu, Z.; Welsch, G. Effects of oxygen and heat treatment on the mechanical properties of alpha and beta titanium alloys. Metall. Trans. A 1988, 19, 527-542. [CrossRef]

4. Chern Lin, J.H.; Moser, J.B.; Taira, M.; Greener, E.H. Cu-Ti, Co-Ti and Ni-Ti systems: Corrosion and microhardness. J. Oral Rehabil. 1990, 17, 383-393. [CrossRef]

5. Wang, R.; Welsch, G. Evaluation of an experimental Ti-Co alloy for dental restorations. J. Biomed. Mater. Res. Part B Appl. Biomater. 2013, 101, 1419-1427. [CrossRef]

6. Mihalcea, E.; Hernández, H.V.; Olmos, L.; Jimenez, O. Semi-solid Sintering of Ti6Al4V/CoCrMo Composites for Biomedical Applications. Mater. Res. 2019, 22, e20180391. [CrossRef]

7. Bastwros, M.; Kim, G.Y.; Zhu, C.; Zhang, K.; Wang, S.; Tang, X.; Wang, X. Effect of ball milling on graphene reinforced Al6061 composite fabricated by semi-solid sintering. Compos. Part B Eng. 2014, 60, 111-118. [CrossRef]

8. German, R.M.; Griffo, A.; Liu, Y. Gravitational effects on grain coarsening during liquid-phase sintering. Metall. Mater. Trans. A 1997, 28, 215-221. [CrossRef]

9. Biurrun, T.S.; Ezquerra, B.L.; Cabezas, L.L.; Moreno, J.M.S. Effect of milling conditions and binder phase content on liquid phase sintering of heat treatable WC-Ni-Co-Cr-Al-Ti cemented carbides. Int. J. Refract. Hard Met. 2020, 88, 105202-105209. [CrossRef]

10. Oliver, C.G.; Álvarez, E.A.; García, J.L. Kinetics of densification and grain growth in ultrafine WC-Co composites. Int. J. Refract. Hard Met. 2016, 59, 121-131. [CrossRef]

11. Mousapour, M.; Azadbeh, M.; Danninger, H. Effect of compacting pressure on shape retention during supersolidus liquid phase sintering of $\mathrm{Cu}$ base alloys. Powder Metall. 2017, 60, 393-403. [CrossRef]

12. Levasseur, D.; Brochu, M. Supersolidus liquid phase sintering modeling of Inconel 718 superalloy. Metall. Mater. Trans. A 2016, 47, 869-876. [CrossRef]

13. Lal, A.; Iacocca, R.G.; German, R.M. Densification during the supersolidus liquid-phase sintering of nickel-based prealloyed powder mixtures. Metall. Mater. Trans. A 1999, 30, 2201-2208. [CrossRef]

14. German, R.M. Supersolidus liquid-phase sintering of prealloyed powders. Metall. Mater. Trans. A 1997, 28, 1553-1567. [CrossRef] 
15. Liu, J.; Lal, A.; German, R.M. Densification and shape retention in supersolidus liquid phase sintering. Acta Mater. 1999, 47, 4615-4626. [CrossRef]

16. Liu, Y.; Tandon, R.; German, R.M. Modeling of supersolidus liquid phase sintering: I. Capillary force. Metall. Mater. Trans. A 1995, 26, 2415-2422. [CrossRef]

17. Bollina, R.; Park, S.J.; German, R.M. Master sintering curve concepts applied to full-density supersolidus liquid phase sintering of 316L stainless steel powder. Powder Metall. 2010, 53, 20-26. [CrossRef]

18. Van Grieken, R.; Markowicz, A. (Eds.) Handbook of X-ray Spectrometry; Marcel Dekker, Inc.: New York, NY, USA, 2001.

19. Mihalcea, E.; Vergara-Hernández, H.J.; Olmos, L.; Jimenez, O.; Arteaga, D.; Salgado-López, J.M. X-ray computed microtomography characterization of Ti6Al4V/CoCrMo biomedical composite fabricated by semi-solid sintering. J. Nondestruct. Eval. 2021, 40, 1-13. [CrossRef]

20. Olmos, L.; Bouvard, D.; Cabezas-Villa, J.L.; Lemus-Ruiz, J.; Jiménez, O.; Arteaga, D. Analysis of Compression and Permeability Behavior of Porous Ti6Al4V by Computed Microtomography. Met. Mater. Int. 2019, 25, 669-682. [CrossRef]

21. Bouvard, D.; Lange, F.F. Relation between percolation and particle coordination in binary powder mixtures. Acta Metall. Mater. 1991, 39, 3083-3090. [CrossRef]

22. Oger, L.; Troadec, J.P.; Bideau, D.; Dodds, J.A.; Powell, M.J. Properties of disordered sphere packings II. Electrical properties of mixtures of conducting and insulating spheres of different sizes. Powder Technol. 1986, 46, 133-140. [CrossRef]

23. Lange, F.F.; Atteraas, L.; Zok, F.; Porter, J.R. Deformation consolidation of metal powders containing steel inclusions. Acta Metall. Mater. 1991, 39, 209-219. [CrossRef]

24. Olmos, L.; Martin, C.L.; Bouvard, D. Sintering of mixtures of powders: Experiments and modelling. Powder Technol. 2009, 190, 134-140. [CrossRef]

25. Vagnon, A.; Rivière, J.P.; Missiaen, J.M.; Bellet, D.; Di Michiel, M.; Josserond, C.; Bouvard, D. 3D statistical analysis of a copper powder sintering observed in situ by synchrotron microtomography. Acta Mater. 2008, 56, 1084-1093. [CrossRef]

26. Fischmeister, H.F.; Arzt, E. Densification of powders by particle deformation. Powder Metall. 1983, 26, 82-88. [CrossRef]

27. Chen, W.; Yamamoto, Y.; Peter, W.H.; Gorti, S.B.; Sabau, A.S.; Clark, M.B.; Nunn, S.D.; Kiggans, J.O.; Blue, C.A.; Williams, J.C.; et al. Cold compaction study of Armstrong Process ${ }^{\circledR}$ Ti-6Al-4V powders. Powder Technol. 2011, 214, 194-199. [CrossRef]

28. Panelli, R.; Ambrozio Filho, F. A study of a new phenomenological compacting equation. Powder Technol. 2001, 114, 255-261. [CrossRef]

29. Panelli, R.; Ambrozio Filho, F. Compaction equation and its use to describe powder consolidation behavior. Powder Metall. 1998, 41, 131-133. [CrossRef]

30. Murray, J.L. The Co-Ti (cobalt-titanium) system. J. Phase Equilibria 1982, 3, 74-85. [CrossRef]

31. Liu, L.H.; Yang, C.; Yao, Y.G.; Wang, F.; Zhang, W.W.; Long, Y.; Li, Y.Y. Densification mechanism of Ti-based metallic glass powders during spark plasma sintering process. Intermetallics 2015, 66, 1-7. [CrossRef]

32. Momeni, H.; Shabestari, S.G.; Razavi, H. Rheology of Al-Cu-Mg pre-alloyed powder in supersolidus liquid phase sintering process. Can. Metall. Q. 2017, 56, 442-449. [CrossRef]

33. Koutsoukis, T.; Zinelis, S.; Eliades, G.; Al-Wazzan, K.; Rifaiy, M.A.; Al Jabbari, Y.S. Selective laser melting technique of Co-Cr dental alloys: A review of structure and properties and comparative analysis with other available techniques. J. Prosthodont. 2015, 24, 303-312. [CrossRef]

34. Xue, Y.; Wang, H.M. Microstructure and wear properties of laser clad TiCo/ $\mathrm{Ti}_{2}$ Co intermetallic coatings on titanium alloy. Appl. Surf. Sci. 2005, 243, 278-286. [CrossRef]

35. Kang, L.M.; Yang, C.; Wang, F.; Li, X.X.; Zhu, D.Z.; Zhang, W.W.; Chen, W.P.; Huan, Y. Designing ultrafine lamellar eutectic structure in bimodal titanium alloys by semi-solid sintering. J. Alloys Compd. 2017, 702, 51-59. [CrossRef]

36. Yan, Z.Q.; Chen, F.; Cai, Y.X.; Yin, J. Influence of particle size on property of Ti-6Al-4V alloy prepared by high-velocity compaction. Trans. Nonferrous Met. Soc. China 2013, 23, 361-365. [CrossRef]

37. Yin, H.; Li, H.; Qu, X.; Khan, M.; Ali, S.; Iqbal, M.Z. Compaction of Ti-6Al-4V powder using high velocity compaction technique. Mater. Des. 2013, 50, 479-483. [CrossRef]

38. Rodrigues, W.C.; Broilo, L.R.; Schaeffer, L.; Knörnschild, G.; Espinoza, F.R.M. Powder metallurgical processing of Co-28\% Cr-6\% Mo for dental implants: Physical, mechanical and electrochemical properties. Powder Technol. 2011, 206, 233-238. [CrossRef]

39. España, F.A.; Balla, V.K.; Bose, S.; Bandyopadhyay, A. Design and fabrication of CoCrMo alloy based novel structures for load bearing implants using laser engineered net shaping. Mater. Sci. Eng. C 2010, 30, 50-57. [CrossRef]

40. Avila, J.D.; Isik, M.; Bandyopadhyay, A. Titanium-Silicon on CoCr alloy for load-bearing implants using directed energy deposition-based additive manufacturing. ACS Appl. Mater. Interfaces 2020, 12, 51263-51272. [CrossRef] [PubMed] 